\title{
Evaluation of Safety and Health Performance on Construction Sites (Kuala Lumpur)
}

\author{
D. M. Yakubu ${ }^{1} \&$ I. M. Bakri ${ }^{1}$ \\ ${ }^{1}$ Universiti Putra Malaysia, Selangor, Malaysia \\ Correspondence: D. M. Yakubu, Department of Environmental Management, Faculty of Environmental Studies, \\ Universiti Putra Malaysia, 43400 UPM Serdang, Selangor, Malaysia. E-mail: yaksmoves@yahoo.com
}

Received: October 7, 2012 Accepted: November 1, 2012 Online Published: March 13, 2013

doi:10.5539/jms.v3n2p100 URL: http://dx.doi.org/10.5539/jms.v3n2p100

\begin{abstract}
Occupational safety and health Act (Act 514) obligate each employer to provide and maintain a safe and healthful workplace for all his employees. Construction is a risky business with a lot of injuries and illness, due to poor safety performances. The aim of the study is to investigate the safety and health performance of contractors on construction sites. A comparative and sensitivity analysis conducted reveal that as allocation to the construction increases so also the rate of accidents increases and that fatal accidents contribute more to the total accidents rates, as such there is need to assess the performance of contractors as regard to safety and health operation. The result of the SHASSIC score reveal that the sites consider for the study were 3 -star in ranking, were its risks/hazards activities are well managed and documented, but still there are other risks/hazards activities that are not taken care off due to negligent on the side of the contractors. The finding affirm the importance of safety program in construction site, as such to ensure successful implementation of the safety program, the following condition must be made; management commitment, safe work condition and safe work habit.
\end{abstract}

Keywords: accident, construction, safety, management, inspection

\section{Introduction}

Part 1V of occupational safety and health act and regulation (Act 514 of 1994) provides for general duties of employers and self employed person to their employees (section 15), to persons other than the employees (section 17) and the duties of an occupies of a place of work to person other than his employees (section 18) obligates each employers to provide and maintain a safe and healthful workplace.

According to international labor organization (ILO), there are more than 100million construction workers worldwide. More than half of these workers are found in Asia, home to two of the biggest developing countries, China and India (Chang, 2008). Construction is a risky business with 13 workers per 100,000 being killed in construction as against 5 per 100,000 in the all-sector average. Construction also exposed workers to a wide range of health problem ranging from asbestosis to back pain, hand-arm vibration syndrome to cement burns (Fact., 2004). The injuries and the health problem associated with the construction show that the industry is the most hazardous occupation and high-risk environment in the world, where workers face a greater risk of work-related fatality or injury, due to poor safety performances.

Despite safety and health regulations in most countries, high rates of injury and fatality persist. In many countries, the procedures intend to prevent such accidents are usually mandated by the appropriate occupational safety authority, (Gee \& Saito., 1997); (Haupt, 2001). In Malaysia for example, the prevailing regulations and legislations regarding safety and health at workplace is the OSHA of 1994. Many scholars and professionals within the construction industry recognize that regulations and legislations by themselves are not enough to bring about the desire goal to zero accidents and incident on construction sites (Ratay, 1997); (Haupt 2001).

What is required as regard to this is adoption and implementation of safety-conscious contractors supported by experienced and trained employees and in order to avoid mishap (accidents) at the workplace (construction sites) OSH management must be practices at all level of the construction from top management to the laborers at workplace. 
In another development, (Vander, Toit, Sikosen, Notje and Evert 2009) expressed that rapid growth in the construction industries and increased accidents has brought about increased threat to occupational safety and health, and as such there have been a number of injuries and fatal in recent years. The aim of this paper is to evaluate/assess the safety and health performance at workplace i.e construction sites. And in order to carry out the evaluation/assessment, there is need to investigate the safety and health performance of contractors at construction sites. Safety and health assessment system in construction (SHASSIC) will be used to evaluate/assess the performance of safety and health at workplace. The safety and health assessment system in construction was designed and developed to assess safety and health performance of contractors and also to take necessary corrective action on OSH performance and management at site.

The result of comparative studies carry out on the types of accidents associated with the construction industry i.e fatal and nonfatal accidents and the result of the sensitivity analysis carried out will determine the need for the assessment of the contractor's performance as regard to safety and health at construction sites.

Complying with safety and health, regulations and legislations, safety in construction site can be improved, if reasonable in philosophy, adequate in detail and worded without ambiguity: legislation and regulations provided a basis for employment and enforcement of good construction practices (Haupt, 2001).

\section{Method and Material}

The data required for the study are of two types;

1) Secondary data, which consist of number of fatal and nonfatal accidents rates and their total number over the period of study i.e 2002 to 2010 , were obtain from the department of occupational safety and health of the Ministry of Human Resources Malaysia. The following analysis are to be carried out on the data;

a) Comparative descriptive analysis of fatal and nonfatal accidents.

b) A sensitivity analysis, in order to determine the variables (fatal and nonfatal rate of accidents) that contribute more to the total number of accidents rates.

2) The primary data, which consist of questionnaire i.e construction industry standard, which will be administer on the two selected construction sites within Kuala Lumpur.

The construction sites selected for the study must be:

3) A Building or Civil Engineering Construction Sites.

4) The contract price must be above RM15million.

5) The number of workers on site must be grater or equal to forty (40).

6) The progress of work must be between $25-75 \%$ completions.

At each of the construction sites three (3) types of questionnaire were administered;

c) Questionnaire for document review (checking) as related to safety and health plan on site.

d) Questionnaire on construction safety and health inspection checklist.

e) Questionnaire for various categories of employees on site.

Safety and Health Assessment System in Construction (SHASSIC) will be used to analysis the questionnaires. SHASSIC is an independent method of assessing/evaluating the safety and health performance of contractors on sites. The weightage system employed in the SHASSIC is aim at making the score quantitative in representing the safety and health performance of the respective contractors.

\section{Analysis and Result}

Table 1 is the record of fatal, nonfatal and the total number of accidents from $2002-2010$ obtained from DOSH 2011. While Figure 1 shows the line graph (trend) of the occurring of fatal and nonfatal accidents rates. 
Table 1. The total number of fatal and non-fatal occupational accident from 2002 to 2010 in Malaysia construction industry obtain from department of safety and health

\begin{tabular}{lllll}
\hline S/no. & Year & Fatal Accident & Non-fatal Accident & Total Accident \\
\hline 1 & 2002 & 25 & 37 & 63 \\
2 & 2003 & 24 & 34 & 58 \\
3 & 2004 & 16 & 17 & 33 \\
4 & 2005 & 63 & 72 & 135 \\
5 & 2006 & 71 & 47 & 118 \\
6 & 2007 & 95 & 86 & 181 \\
7 & 2008 & 72 & 57 & 129 \\
8 & 2009 & 81 & 76 & 157 \\
9 & 2010 & 65 & 54 & 119 \\
\hline
\end{tabular}

Dosh 2011.

Figure 1 indicates that there is no clear positive or negative trend in the number of fatal and nonfatal accidents rates from $2002-2010$, nor is there a perfect correlation between fatal and nonfatal rates.

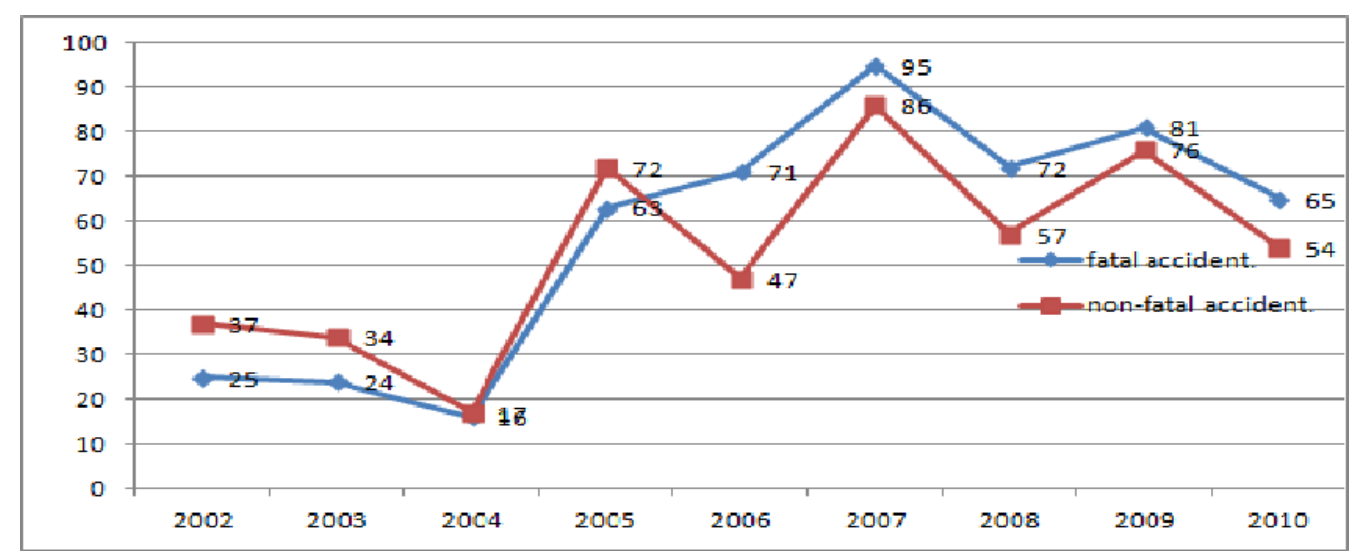

Figure 1. Line graph fatal/nonfatal accident from 2002 to 2009

From $2002-2004$ there have been a drop in the number of fatal and nonfatal accidents rates, this is due to the fact that only USD 3.68billion were earmark for new projects in the construction industry in the 8MP (2001 2005 ) and this include USD 263million for KLIA Infrastructure. In 2005 toward the end of the action plan the rate of the fatal and nonfatal accidents increases. In 2006, the rates of fatal accidents increase while that of nonfatal accidents decrease and it was in this year that the Malaysia government unveiled its 9MP, in which the plan strategies clearly have a impact on the construction industry meeting the housing needs, and improving urban services, building basic infrastructure, improving transportation facilities etc. It is in 2007 that the construction industry experience high rate of fatal and nonfatal accidents rates, which is due to the active implementation of the 9MP, the value of construction project in 2007 exceed RM500.000.00 increased significantly by RM87.97 billion i.e an increase of $49.2 \%$ as compare to the total awarded in 2006 (RM58.96 billion).

Some of the projects implemented in 2007 are the Double tracking project from Ipoh to Padang Besar worth RM12.49 billion, the Double tracking project between Seremban and Gemas worth RM3.45 billion and the South Klang Valley Expressway project with value of RM1.10 million. A report on the midterm review of the Malaysia government show that the implementation plan is on track.

In 2008, due to global financial crisis, there were no sign that the private sector will increase its investment in the near future due to the unpredictable nature of the external factors: the discomfort experienced in local politics and the increase in food price which impact household expenditure, there is no indicator which stimulate the demand in construction as shown in 2007 and this subsequently lead to drop in number of fatal and nonfatal accidents rates when compare to 2007. In 2009, the rate of fatal and nonfatal accidents rates increases more 
when compare to 2008 , this is as a result of the government response to global financial crisis in which its announced a stimulus package of RM60 billion and this package have an impact on the construction industry.

There is an drop in the number of fatal and nonfatal accidents rates in 2010, which is as a result of economic setback which affected the industry as everything was stagne in the construction industry, as no new work done, there were lot of project that were delay due to economic downfall. Therefore, from the comparative analysis carry out, it was observed that increase in government funding to construction industry, increase the rates of accidents in the construction industry.

To determine the actual contribution of non-fatal accidents and fatal accidents to the rate of total accidents over the period of 2002 to 2010 , a sensitivity analysis of leave one is used, using simple linear regression. Sensitivity analysis is a technique used to determine how different value of an independent variable will impact a particular variable under a given set of assumption. Also it can help in determining which of parameters (variables) the key driver of a model results is.

Table 2. Sensitivity analysis of leave one using simple linear regression with $r^{2}$ of 0.817 for non-fatal and fatal analysis

\begin{tabular}{llll}
\hline & Rsq. & AR & Contribution to total \\
\hline Fatal & 0.961 & 0.144 & $53.53 \%$ \\
Non-fatal & 0.942 & $\underline{0.125}$ & $46.47 \%$ \\
& & 0.269 & \\
\hline
\end{tabular}

Sources: Researcher Analysis.

Therefore, from the Table 2, 53.53\% of the accidents that occur in the construction sector from the 2002 to 2010 are fatal accidents i.e deadly, while $46.47 \%$ make up non-fatal accidents. The non-fatal accidents can be permanent disability or non-permanent disability. As such, there is the need to assess the performance of the construction firms/companies in Malaysia as regard to their safety and health measures adopted at the construction sites. Therefore a system of assessment called Safety and Health Assessment System in Construction Industry (SHASSIC) will be used to assess the contractor's performances.

Table 3 shows the scores of the two selected construction sites for the study in Malaysia. Site A, show a better result when compare to site $\mathrm{B}$, the overall score calculated of the two sites were also included in the table.

Table 3. Analysis/result of SHASSIC

\begin{tabular}{|c|c|c|c|c|}
\hline components & Site A & Site B & $\begin{array}{l}\text { Overall } \\
\text { A \& B }\end{array}$ & scores \\
\hline $\begin{array}{l}\text { Document } \\
\text { check. }\end{array}$ & $\begin{array}{l}\text { Total number 'C' scores } X 40 \\
(63-\text { Number of NA). } \\
\frac{53}{63} \times 40 . \\
\end{array}$ & $\begin{array}{l}\text { Total number 'C' scores } X 40 \\
(63-\text { Number of NA). } \\
\frac{21}{63} \times 40 \quad=14.74 \%\end{array}$ & $25.04 \%$ & \\
\hline $\begin{array}{l}\text { Workplace } \\
\text { Inspection }\end{array}$ & $\begin{array}{l}\frac{\text { Total number ' } C \text { ' scores }}{(310-\text { Number of NA) }} 40 . \\
\frac{55}{310} \text { X } 40 \\
\\
310=26.19 \%\end{array}$ & $\begin{array}{l}\frac{\text { Total number ' } C \text { ' scores }}{(310-\text { Number of NA) }} 40 . \\
\frac{24}{310} 40 \\
\begin{array}{l}310-209=9.19 \%\end{array}\end{array}$ & $17.85 \%$ & \\
\hline $\begin{array}{l}\text { Employees } \\
\text { Interview. }\end{array}$ & $\begin{array}{l}\frac{\text { Total number 'C' scores }}{(330-\text { Number of NA) }} \times 20 \\
\frac{225}{330-48}=15.96 \%\end{array}$ & $\begin{array}{l}\frac{\text { Total number ' } C \text { ' scores }}{(330-\text { Number of NA })} 20 \\
\frac{148}{330} \times 20=55=10.76 \%\end{array}$ & $13.36 \%$ & \\
\hline
\end{tabular}

Sources: Researcher Analysis.

Figure 2 indicates the contribution of the 3 components i.e Document check (25.04\%), Workplace inspection $(17.85 \%)$ and Employee's interview (13.36). 


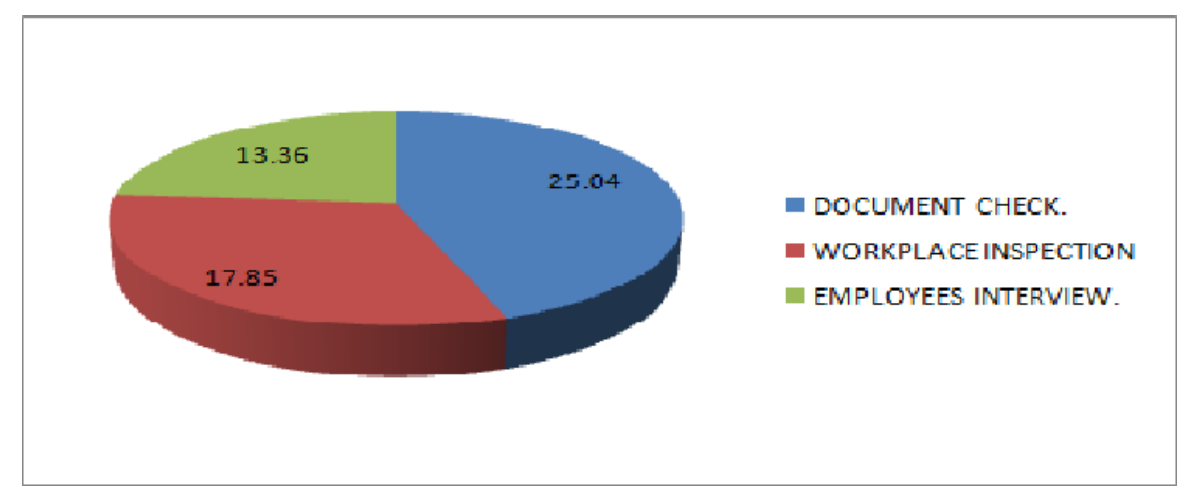

Figure 2. SHASSIC scores

\section{A- DOCUMENT CHECK}

In Document checking there are 63 questions, which are classified under 9 different categories. Table 3.4 shows the 9 categories of document check with the overall result of the two sites, i.e obtained and total score.

Table 4. Scores of document check

\begin{tabular}{lll}
\hline Components & Obtained scores & Total scores \\
\hline OSH Policy & 12 & 12 \\
OSH Organization. & 17 & 22 \\
HIRARC & 5 & 10 \\
Training and Promotion & 11 & 16 \\
Machinery Management & 7 & 11 \\
Material Management & 5 & 9 \\
Emergency Response Plan (ERP) & 4 & 8 \\
Accident Investigation and Reporting & 3 & 11 \\
Record Management and Performance & 10 & 18 \\
Monitoring. & & \\
\hline
\end{tabular}

Source: Researcher Analysis.

As regard to document check, only Accident Investigation and Reporting document score that is below average, while some are below average some are little above the average. Only document regard to OSH Policy statement of the organizations that is $100 \%$ perfect Figure 3 .

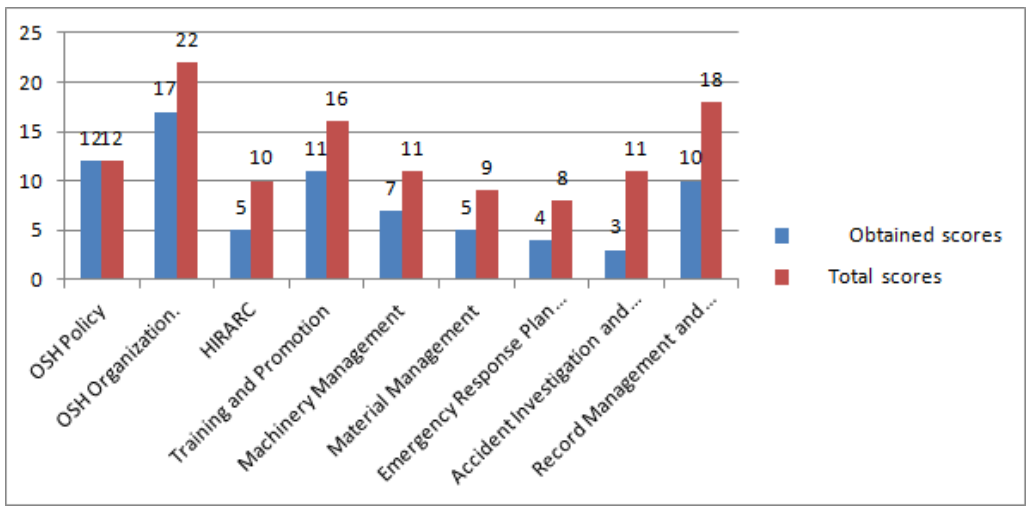

Figure 3. Overall document check 


\section{B- Workplace Inspection}

In workplace inspection, there are 310 items that need to be inspected and these items are classified under 22 categories. Table 5 shows the obtained score and the total score from the workplace inspection carried out.

Table 5. Scores of workplace inspection

\begin{tabular}{llll}
\hline COMPONENTS & OBTAINED SCORES & TOTAL SCORES. \\
\hline Machinery. & 10 & 17 & 0 \\
Scaffold. & 0 & 27 \\
Signages colour code & 6 & 16 \\
Notice. & 4 & 0 \\
Ventilation. & 0 & 25 \\
Housekeeping & 15 & 1 \\
Illumination/lighting & 1 & 3 \\
Fire protection & 3 & 39 \\
Personal protective equipment. & 17 & 13 \\
Barricade for hazard area. & 5 & 9 \\
Acces/egress & 4 & 6 \\
Suitable working tools/equipment. & 6 & 1 \\
Electric safety & 0 & 1 \\
Prevention of falling object. & 0 & 2 \\
Hazardous substance & 2 & 2 \\
Safety policy & 1 & 3 \\
Perimeter harding & 1 & 15 \\
Vehicular traffic management. & 0 & 1 \\
Toilet. & 1 & 1 \\
First aid box. & 1 & 1 \\
Designated rest area & 1 & 2 \\
Water ponding. & 1 & \\
\hline
\end{tabular}

Source: Researcher Analysis.

The result of each of the 22 categories of items consider for the workplace inspection are shown in Figure 4 . The personnel protective equipment provided for the workers at workplace has the poorest result which means that the facilities provided for the protection of these at work is inadequate which make the workers to be working with hazard at their workplace. Only five categories of item show s good result while other results are below average or little above average.

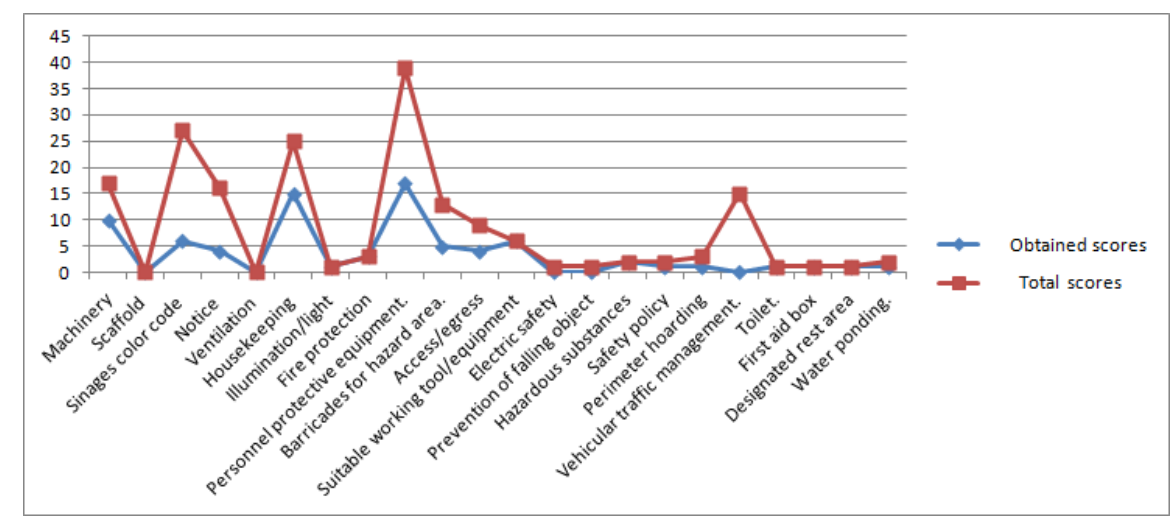

Figure 4. Workplace inspection line graph 


\section{C- Employee's Interview}

In employee's interview, three (3) types of interview were conducted for the study:

i- Management Interview

Under management interview, one person is selected for the interview at each sites and twelve (12) different types of questions were available for the interviewer and these questions are classified under seven (7) categories. Table 6 shows the overall result of the interview.

Table 6. Result of management interview

\begin{tabular}{lll}
\hline Category & Obtained scores & Total scores. \\
\hline OSH Policy & 3 & 4 \\
OSH Organization & 3 & 4 \\
HIRARC. & 4 & 6 \\
Training \& Promotion & 1 & 2 \\
Material Management & 2 & 4 \\
Emergency Preparedness' & 2 & 2 \\
Accident Investigation and Reporting. & 1 & 2 \\
\hline
\end{tabular}

Sources: Researcher Analysis.

The management personnel have good knowledge of OSH Management system practice in their sites, a little improvement in the knowledge of HIRARC and Material Management on sites is required as show in Figure 5.

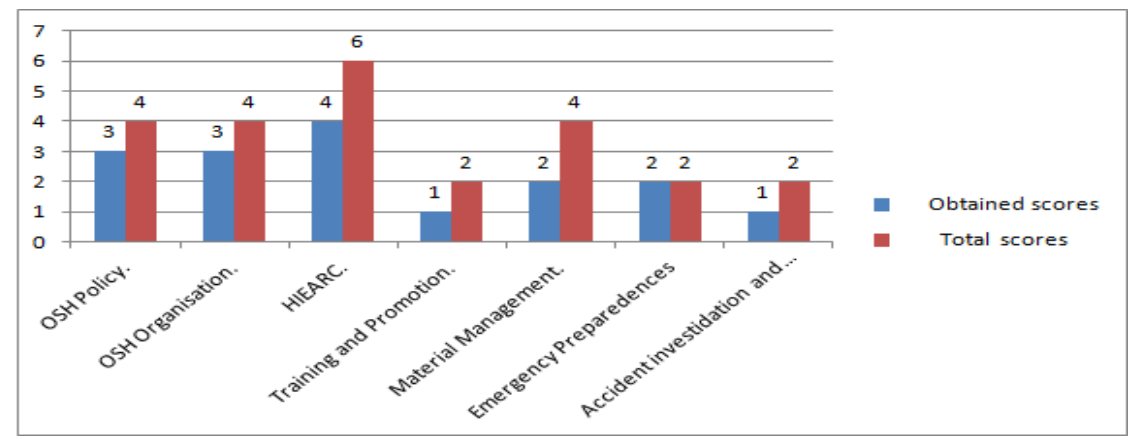

Figure 5. Management interviews

ii- Safety and Health Committee Members

In safety and health committee members' interview, six (6) different types of questions are available for 3committee members at each site. The six questions are classified under 4 categories. Table 7 shows the overall result of the interview.

Table 7. Result of safety and health committee member's interview

Source: Researcher Analysis.

\begin{tabular}{lll}
\hline Component & Obtained scores & Total scores \\
\hline OSH Policy & 5 & 6 \\
OSH Organization & 11 & 12 \\
Training and Promotion & 2 & 3 \\
Emergency Prepardeness & 0 & 6 \\
\hline
\end{tabular}

In the knowledge of Emergency Preparedness the committees members score zero out of six, while the rest items categories show a good results. As such the committee's members need to improve their knowledge in emergency preparedness as this has to do with what do in case of an emergency on site as shown in Figure 6. 


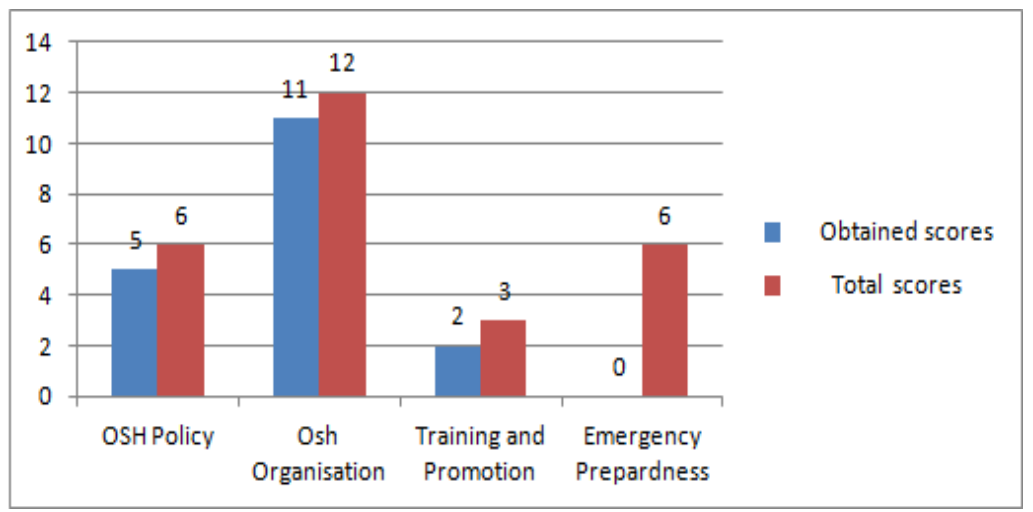

Figure 6. Safety and health committee interview overall result

\section{iii- Construction Workers Interview}

In construction workers interview, five (5) construction workers were selected for the interview at each sites and a total of 30 questions are available for each workers. The 30 questions are classified under 8 categories. Table 8 shows the overall result of the construction workers interview.

Table 8. Result of construction workers interview

\begin{tabular}{lll}
\hline Components. & Obtained scores & Total scores \\
\hline OSH Policy & 34 & 80 \\
OSH Organization. & 90 & 120 \\
HIRARC & 38 & 40 \\
Training and Promotion & 47 & 80 \\
Material and Equipment & 1 & 2 \\
Material Management & 4 & 4 \\
Emergency Preparedness & 89 & 140 \\
Accident Investigation \& Reporting. & 36 & 40 \\
\hline
\end{tabular}

Source: Researcher Analysis.

In the Figure 7, it can be observed that most construction workers lack adequate knowledge of OSH Management System at their workplace, only the result of Material Management and Machinery and Equipment Management that show good result. Majority of the workers have no knowledge of their company statement of intent as regard to their safety at the workplace etc.

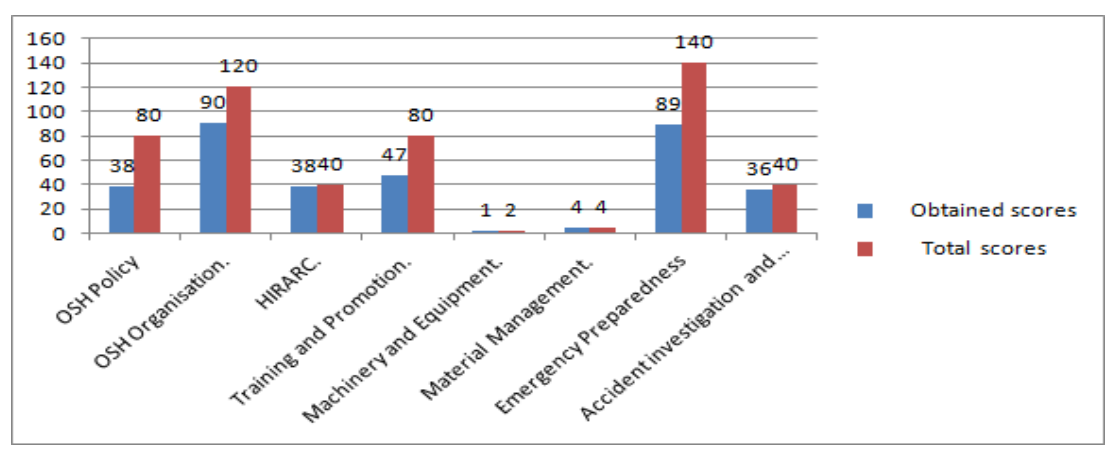

Figure 7. Overall results of construction workers interview 


\section{Conclusion Remark}

Based on the analysis carried out on the type of accidents in construction sites, it was observed that there is no perfect correlation between fatal and nonfatal accidents rates over the period of study and that accident tend to increase as government allocation to the construction increases.

Also, a useful information as regard to the contribution that fatal and nonfatal accidents have on the total number of accidents was established, from the result fatal accidents contribute $53.53 \%$ while nonfatal accidents contribute $47.46 \%$. Due to non availability of enough data the study did not make any future prediction, as for proper prediction to be made the sample size must be up to twenty in sizes. Based on the result of the comparative study and the sensitivity analysis carried out, there is need to evaluate/assess the performance of safety and health at construction sites. The aim is to evaluate and to determine the performance level of the contractors as regard to safety and health operation at construction sites. As such the major conclusion of the study will be drawn from the average SHASSIC score of the two sites, using the star ranking: Table 9 show the star ranking of the sites.

Table 9. Star ranking result

\begin{tabular}{lll}
\hline $\begin{array}{l}\text { SHASSIC } \\
\text { SCORE } \%)\end{array}$ & Star Awarded & Justification \\
\hline $55-69$. & $* * *$ & $\begin{array}{l}\text { Potential and significant workplace high risks/hazards are } \\
\text { managed and documented but there are few medium risks } \\
\text { work activities are neglected. }\end{array}$ \\
\hline
\end{tabular}

Source: Researcher Analysis.

The total average SHASSIC score of the two sites is $56.25 \%$, this score fall under three star in ranking, the result of the SHASSIC score reveal that the construction sites consider for this study are 3 - star in ranking, which means that its risks/hazards activities as regard to safety document, proper housekeeping (workplace inspection) and employees understanding of OSH management system at sites are well managed and documented, but still there are other risks/hazards activities that are not taken care off due to negligent on the site of the contractors and the clients.

Those item or components that are not well managed and documented are analysis and identified in the analysis of the SHASSIC components i.e Document, Workplace Inspection and Employees Interview. However, according to (Reese \& Eidson, 1999), that incidents and injuries (Accidents) on construction sites are a direct result of not adhering to their established safety procedures. Therefore, it is evident that a focused dedication and effort toward safety program is needed at construction sites. The findings of the study affirm the importance of safety program in construction sites.

As such, to ensure that successful safety programs are implemented on sites, the following condition must be made:

1) Management Commitment; this includes leadership, vision, and direction, statement of objectives, commitment, supervision, safety analysis, and prevention planning.

2) Safe Work Condition; this includes proper housekeeping, proper site layout and space availability.

3) Safe Work Habit; this includes awareness, good communication, personal attitude, safety culture, positive groups and personal competency.

In order words, a successful safety program is based on the commitment and the participation of management and workers in policymaking and in the establishing an adequate feedback system that will lead to continuous improvement of the safety program.

\section{References}

Chang, D. O. (2008). Global construction and asian workers: Expansion of TNCs in asia and implications for labour.

Fact. (2004). European Agency for Safety at Work.

Gee, A. F., \& Saito., K. (1997). Construction Loads and Other Safety Measures Specified by U.S., U.K and Japanese Bridge Standard. 
Haupt, T. C. (2001). The performance approach to construction worker safety and health. University of Florida. Haupt. (2001). The performance approach to construction workers safety and health.

Ratay, R. T. (1997). Construction Safety Affected by Codes and Standards.

Reese, C., \& Eidson, J. (1999). Handbook of OSHA construction safety and health.

Vander, M. T., Toit, W. D., Sikosen, Z., Notje, N., \& Evert, P. (2009). Managing construction health and safety. Conference on managing construction health and safety "optimising on-site health and safety", 20-100. 